\title{
PERBANDINGAN MENGONSUMSI BERBAGAI JENIS MINUMAN BERKAFEIN (KOPI, TEH HIJAU, DAN MINUMAN BERENERGI) TERHADAP WAKTU REAKSI
}

\author{
Wigit Kisworo $^{1}$, Hamidie Ronald Daniel Ray ${ }^{1,2,3}$, Ugelta Surdiniaty ${ }^{3}$ \\ ${ }^{1}$ Pendidikan Kesehatan dan Rekreasi, Universitas Pendidikan Indonesia, Bandung, Indonesia; \\ ${ }^{2}$ Fakultas Human Sciences, Universitas Kanazawa, Ishikawa, Jepang; \\ ${ }^{3}$ Pendidikan Olahraga Sekolah Pascasarjana, Universitas Pendidikan Indonesia, Bandung, Indonesia.
}

\begin{abstract}
Generally, the aim of this research to know the comparison of caffeine drinks through the result of reaction time after consumption coffee, green tea, and energy drink by the same amount of caffeine. The way to gather the data is using purposive sampling, the population that chosen by researcher is 10 respondents' college students of Ilmu Keolahragaan batch 2016. For data analysis, using SPSS 21 program for windows and Statistical calculation that used is One-Way ANOVA continues with Post Hoc Tukey. The average of result from time reaction on Speed Anticipation Reaction is 1.263 (placebo), 1,257 (green tea), 1.271 (energy drink), and 1.358 (black coffee). For Body Reaction Time Test (visual) shows the average around 1.239 (placebo), 0.245 (green tea), 0.257 (green tea), and 0.244 (black coffee). While on Whole Body Reaction Time Test (auditory) shows the average0.239 (placebo), 0.239 (green tea), 0.274 (energy drink), and 0.263 (black coffee). The signification value from three time reaction test are (Speed Anticipation Reaction Sig. 0.706 $>0.05$, Whole Body Reaction (visual) Sig. 0.877 > 0.05, and Whole Body Reaction (auditory) Sig. $0.348>0.05$ ) all of the result above 0.05. Hence, it can be conclude there is no significantly difference through time reaction result after consumption kind of caffeine drinks with the same concentration.
\end{abstract}

Keywords: caffeine, reaction time, speed anticipation reaction, whole body reaction

Korespondensi: Wigit Kisworo, E-mail: kisworowigit@gmail.com, Pendidikan Kesehatan dan Rekreasi, Universitas Pendidikan Indonesia, Bandung, Indonesia. 


\section{PENDAHULUAN}

Dalam pengaturan olahraga, kafein dikonsumsi sebelum bertanding oleh $74 \%$ atlet elit nasional dan internasional, berbasispada konsentrasi kafein ditemukan di sampel urin yang diperoleh untuk analisis doping. Kafein dalam olahraga dikaitkan dengan manfaat fisik yang berasal dari konsumsi dalam berbagai macam aktivitas olahragadan penghapusan kafein dari daftarzat terlarang yang diterbitkan oleh World Antidoping Agency (WADA) pada tahun $2008^{1}$.

Minuman energi dan kopi menyatakan bahwa dapat meningkatkan kinerja, konsentrasi dan kecepatan reaksi, meningkatkan kewaspadaan, merangsang metabolisme, dan membuat orang merasa lebih energik. Studi baru menemukan kopi tidak menaikkan tekanan darah atau kolesterol, mungkin memiliki sifat anti kanker, mengurangi kemungkinan berkembangnya diabetes, dan membantu melindungi pria dari penyakit Parkinson ${ }^{2}$.

Sementara itu, konsentrasi kafein bervariasi antara minuman yang berbeda dengan kopi, pada umumnya memiliki nilai tertinggi dibandingkan teh, dan beberapa minuman energi. Sebuah variasi yang signifikan dalam konsentrasikafein dalam kategori minuman juga terdapat pada kasus kopi dan teh. Teh hijau mengandung kafein, namun ada variabilitas yang besar dalam kandungan kafein menurut jenis teh hijau. Mengingat kafein itu terjadi secara alami pada minuman yang mengandung kafein akan bervariasi karena varietas tanaman, kondisi pertumbuhan lingkungan atau metode pembuatan yang digunakan ${ }^{3}$.

Waktu reaksi adalah waktu yang telah berlalu antara presentasi dari stimulus sensorik dan respon perilaku selanjutnya. Memiliki waktu reaksi yang baik memungkinkan seseorang bertindak sedikit lebih cepat dari lawan mereka, sehingga memberi mereka keuntungan dalam persaingan ${ }^{4}$.Waktu reaksi dibagi menjadi 5 bagian yaitu, datangnya rangsangan pada reseptor (telinga, mata, dan kulit), menentukan rangsangan ke sistem syaraf pusat (SSP), membangun dan melepaskan sinyal yang efektif (perintah), meneruskan perintah tersebut dari SSP ke otot, dan merangsang otot dan membuat awal gerakan.Tahap 1 sampai 4 adalah yang disebut dengan waktu reaksi ${ }^{5}$. Faktor lain yang memengaruhi waktu reaksi diantaranya adalah kelelahan, gangguan psikologis, mengkonsumsi minuman beralkohol, siklus pernapasan, tremor, tipe kepribadian, latihan, penggunaan obat-obatan, stress, intelegensi, dan cedera otak ${ }^{6}$.

Kafein (1,3,7- trimethylxanthine) adalah alkaloid alami yang ditemukan dalam berbagai variasi kuantitas dalam kacang, daun, dan buah ${ }^{1}$. Beberapa sumber kafein umum adalah kacang kola (Cola acuminate), biji coklat (Theobroma cacao), yerba mate (Ilex paraguariensis), dan guarana berry (Paullinia cupana); namun, biji kopi panggang (Coffea Arabica dan Coffea robusta), dan daun teh (Camelia siniensis) adalah sumber makanan utama kafein ${ }^{7}$. Ada maupun tidak ada perbedaan kimia antara kafein sintetis dan alami bersumber dari kafein. Kafein paling sering dikonsumsi dalam minuman seperti kopi $(71 \%)$, minuman ringan $(16 \%)$, dan teh $(12 \%)^{8}$. Pasar untuk minuman berkafein telah meningkat dalam dekade terakhir dengan pengenalan minuman fungsional, termasuk kategori minuman energi, serta minuman lainnya seperti minuman olahraga berkafein, jus, dan air ${ }^{8}$. Selain minuman ini, kafein juga ditemukan dalam cokelat dan dalam berbagai macam obat-obatan seperti formulasi pereda sakit dan suplemen $\operatorname{diet}^{3}$.

Mengkonsumsikafein dapat mempromosikan peningkatan kinerja manusia ${ }^{9}$. Efek kafein terhadap kinerja terkait dengan mekanisme sentral dan perifer. Efeknya kafein pada sistem saraf pusat (SSP) terkait dengan blokade reseptor adenosin yang mencegah penurunan aktivitas saraf dan selanjutnya peningkatan perekrutan $\operatorname{otot}^{10}$. Secara periferal,peningkatan katekolamin plasma dan aktifitas glikolisis meningkatkan ketersediaan energi untuk otot aktif selama latihan'.

Sebagai konsekuensi dari efek sentral dan perifer, kafein meningkatkan kinerja dalam melibatkan fungsi kerja psikomotor seperti ketangkasan dan akurasi pengambilan keputusan ${ }^{11}$. Kafein meningkatkan kecepatan dan akurasi sepak bola ${ }^{12}$. Demikian pula bahwa kafein meningkatkan koordinasi, kecepatan, dan ketepatan selama protokol tertentu mengukur keterampilan rugby ${ }^{13}$.Selain itu, penelitian juga menunjukkan bahwa kafein meningkatkan kinerja selama beberapa sprint, khususnya selama sprint pertama dalam satu set beberapa sprint ${ }^{14}$. Studistudi ini menunjukkan bahwa suplementasi kafein meningkatkan kekuatan, kecepatan, kelincahan, perhatian dan waktu reaksi. Semua variabel ini merupakan penentu penting kinerja dalam pertempuran olahraga ${ }^{15}$. 
Penelitian ilmiah mengenal efek kafein tehadap performa individu dalam olahraga beregu hampir tidak mungkin terlaksana dan jarang dilakukan. Perlu diketahui, selain meningkatkan daya tahan dan memberikan keuntungan ergogenik, kemampuan kafein dalam mempercepat reaksi, menstabilkan mental, serta memperbaiki ketahanan perhatian fokus dan perhatian terbagi menawarkan janji surga bagi atlet yang melakoni olahraga beregu, seperti bola basket, sepak bola, bisbol, dan olahraga yang membutuhkan reaksi cepat lainnya seperti tenis, anggar, tinju, dan balap mobil. Dengan kata lain, kafein akan mendorong atlet lari, renang, dan balap sepeda untuk menempuh lintasan yang lebih jauh dengan lebih cepat. Kafein tidak hanya memberikan keuntungan dengan cara ini, tetapi juga melalui efeknya terhadap beberapa faktor pendukung kesuksesan lainnya ${ }^{16}$. Menurut data saat ini, peningkatan reaksi setelah mengkonsumsi kafein boleh dibilang signifikan, baik ketika subjek dalam kondisi bugar maupun letih ${ }^{17}$. Dalam kecepatan reaksi dan pengambilan keputusan secara tepat, keduanya diperantarai oleh kafein, adalah dua komponen penting untuk mencapai performa yang baik dalam cabang olahraga beregu dan olahraga lain yang mementingkan kecepatan ${ }^{18}$.

Dengan demikian, dalam secangkir kopi, teh hijau, dan minuman berenergi yang sering dikonsumsi sama-sama mengandung kafein namun dalam jumlah yang berbeda. Sehingga akan menimbulkan pengaruh yang berbeda pula karena adanya perbedaan jumlah kafein di dalamnya. Namun, apabila ketiga jenis minuman tersebut memiliki jumlah kafein yang sama maka tidak menuntut kemungkinan akan mendapatkan pengaruh yang sama seperti meningkatkan kinerja, konsentrasi dan kecepatan reaksi. Berdasarkan masalah yang telah diungkapkan, maka penelitian ini bertujuan untuk mengetahui bagaimana perbandingan dari setiap jenis minuman berkafein terhadap waktu reaksi yang dihasilkan setelah mengkonsumsi kopi, teh hijau, dan minuman berenergi dengan jumlah kafein yang sama.

\section{METODE PENELITIAN}

Penelitian ini menunjukkan fokus penelitian yang dikaji adalah analisis karakteristik sampel yang melakukan tes dengan mengkonsumsi kafein yang terkandung dalam kopi, teh hijau dan minuman berenergi.Sampel penelitian adalah 10 orang mahasiswa baik putra maupun putri dengan jumlah yang sebanding. Teknik pengambilan sampel dilakukan secara Purposive Sampling yaitu teknik pengambilan sampel dengan menggunakan pertimbangan tertentu. Pertimbangan pengambilan sampel yang diambil pada penelitian ini berdasarkan atas :
1) Mahasiswa Program Studi Ilmu Keolahragaan Angkatan 2016.
2) Tidak mengkonsumsi kafein setiap hari secara teratur.
3) Tidak memiliki masalah yang serius terhadap minuman berkafein.
4) Tidak memiliki riwayat penyakit jantung.
5) Tidak memiliki riwayat penyakit lambung.
6) Tidak merokok dan meminum minuman beralkohol.

Tabel 1. Pemberian Kafein Pada Waktu Reaksi.

\begin{tabular}{|c|c|c|c|c|}
\hline \multirow{2}{*}{$\begin{array}{r}\text { Minggu } \\
\text { Hari } \\
\end{array}$} & \multicolumn{2}{|c|}{ Pertama } & \multicolumn{2}{|c|}{ Kedua } \\
\hline & Selasa & Kamis & Selasa & Kamis \\
\hline \multicolumn{5}{|c|}{ Puasa kafein 1 hari sebelum pengujian } \\
\hline \multirow{6}{*}{$\begin{array}{c}\text { Pemberian Kafein } \\
\text { Pada Tes Waktu } \\
\text { Reaksi }\end{array}$} & & Konsumsi 50 mg Kafein & & Plasebo \\
\hline & Minuman Energi & Kopi Hitam & Teh Hijau & Air Mineral \\
\hline & \multicolumn{4}{|c|}{ Istirahat 60 menit } \\
\hline & \multicolumn{4}{|c|}{ Tes Waktu Reaksi } \\
\hline & $\begin{array}{l}\text { Speed Anticipation } \\
\text { Reaction Test }\end{array}$ & $\begin{array}{l}\text { Speed Anticipation } \\
\text { Reaction Test }\end{array}$ & $\begin{array}{l}\text { Speed Anticipation } \\
\text { Reaction Test }\end{array}$ & $\begin{array}{l}\text { Speed Anticipation } \\
\text { Reaction }\end{array}$ \\
\hline & $\begin{array}{c}\text { Whole Body Reaction Time } \\
\text { Test (visual \& auditory) }\end{array}$ & $\begin{array}{c}\text { Whole Body Reaction } \\
\text { Time Test (visual \& } \\
\text { auditory) }\end{array}$ & $\begin{array}{c}\text { Whole Body Reaction } \\
\text { Time Test (visual \& } \\
\text { auditory) }\end{array}$ & $\begin{array}{c}\text { Whole Body Reaction } \\
\text { Time Test (visual \& } \\
\text { auditory) }\end{array}$ \\
\hline
\end{tabular}


Teknik pengumpulan data dalam penelitian ini yaitu diambil dari 10 orang sampel Mahasiswa Ilmu Keolahragaan. Seluruh sampel melakukan empat kali pengujian dengan waktu yang sama namun dilakukan setelah $\geq 2$ hari dari penelitian sebelumnya. Ketiga jenis minuman berkafein yang akan dikonsumsi yaitu, minuman berenergi, kopi hitam, teh hijau, dan penelitian terakhir menggunakan air mineral sebagi plasebo. Masing - masing dari ketiga minuman tersebut mengandung $50 \mathrm{mg}$ kafein.

Sampel yang ikut berpartisipasi melakukan pengujian selama satu kali dalam sehari. Sebelum melakukan pengujian, sampel mengkonsumsi minuman berkafein dengan jumlah kafein yang telah ditentukan oleh peneliti. Setalah 60 menit mengkonsumsi minuman berkafein, sampel melakukan pengujian terhadap waktu reaksi yang pertama yaitu Speed Anticipation Reaction Test dan selanjutnya dengan pengujian waktu reaksi dengan menggunakan Whole Body Reaction Time Test.

Data dianalisis secara statistik dengan menggunakan aplikasi Statistikal Product and Service Solution (SPSS) dengan analisis One Way Anova dilanjutkandengan Uji Post Hoc Tukey. Tingkat kepercayaan analisis data pada penelitian ini adalah $95 \%$, sehingga nilai $\alpha$ untuk penelitian ini adalah 0,05 .

\section{HASIL PENELITIAN}

Tabel 2 . Hasil Analisis Deskriptif Tes Waktu Reaksi.

\begin{tabular}{cccccccccc}
\hline & \multicolumn{2}{c}{ Plasebo } & \multicolumn{2}{c}{ TH } & & ME & & KH & \\
\cline { 2 - 10 } & Mean & SD & Mean & SD & Mean & SD & Mean & SD & Sig. \\
\hline $\begin{array}{c}\text { Speed Anticipation } \\
\text { Reaction }\end{array}$ & 1,263 & 0.264 & 1.257 & 0.186 & 1.271 & 0.192 & 1.358 & 0.227 & 0.706 \\
\hline $\begin{array}{c}\text { Whole Body } \\
\begin{array}{c}\text { Reaction Time }- \\
\text { visual }\end{array}\end{array}$ & 0.250 & 0.048 & 0.245 & 0.036 & 0.257 & 0.028 & 0.244 & 0.047 & 0.877 \\
\hline $\begin{array}{c}\text { Whole Body } \\
\text { Reaction Time - } \\
\text { auditory }\end{array}$ & 0.239 & 0.054 & 0.239 & 0.064 & 0.274 & 0.036 & 0.263 & 0.053 & 0.348 \\
\hline
\end{tabular}

1. Speed Anticipation Reaction Test

Pada tabel 1 diperoleh nilai rata-rata dari minuman yang diujikan pada tes Speed Anticipation Reactiondengan masing-masing nilai sebesar 1,263 sec untuk plasebo, 1,257 sec untuk teh hijau, 1,271 sec untuk minuman energi dan 1,358 sec pada kopi htam. Nilai signifikansi dari tes Speed Anticipation Reaction sebesar 0.706. Berikut ini adalah nilai perbandingan dari hasil tes waktu reaksi pada Speed anticipation Reaction Test: 


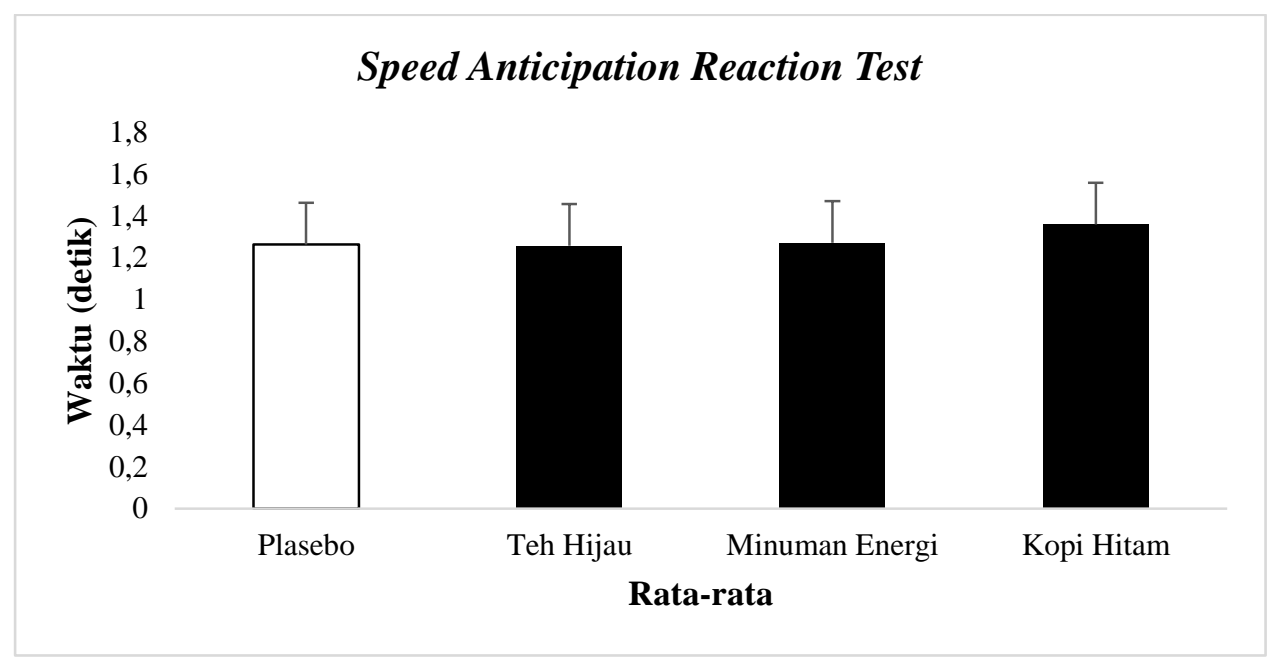

Gambar 1. Nilai Perbandingan Speed anticipation Reaction Test

2. Whole Body Reaction Time Test (visual) Pada tabel 1 diperoleh nilai rata-rata dari minuman yang diujikan pada tes Whole Body Reaction Time Test (visual)dengan masingmasing nilai sebesar $0,250 \mathrm{sec}$ untuk plasebo, $0,245 \mathrm{sec}$ untuk teh hijau, 0,257 sec untuk minuman energi dan 0,244 sec pada kopi hitam. Nilai signifikansi dari tes Whole Body Reaction Time Test (visual) sebesar 0,877.Berikut ini adalah nilai perbandingan dari hasil tes waktu reaksi pada Whole Body Reaction Time Test (visual):

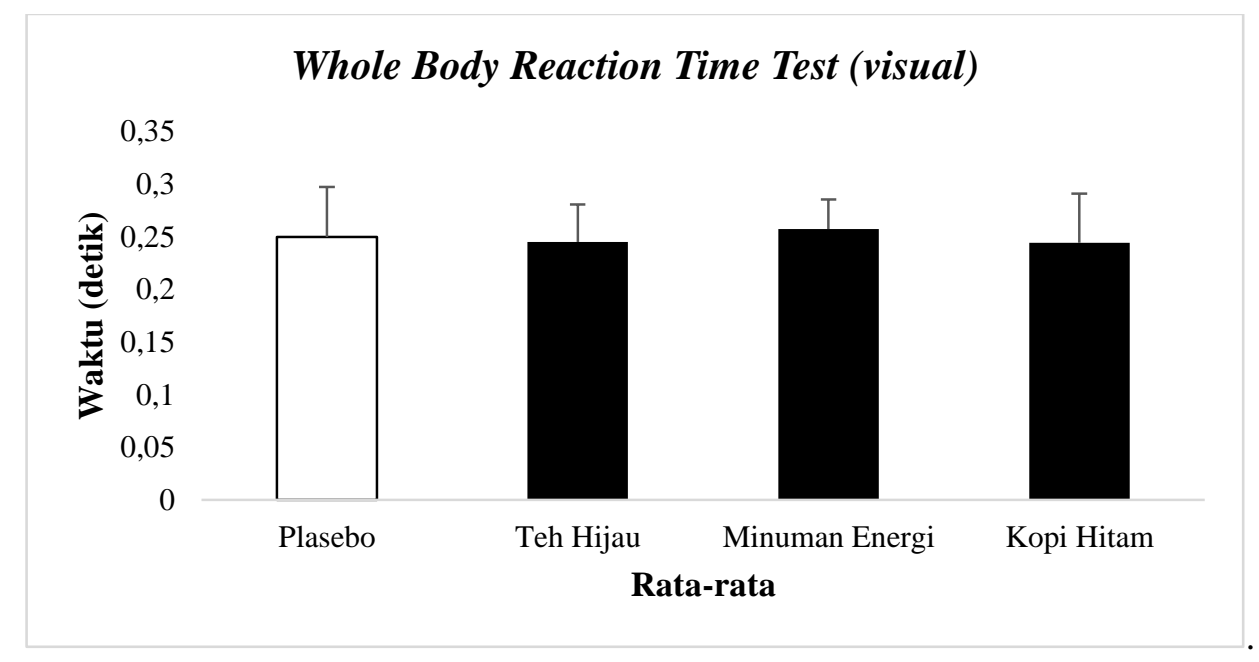

Gambar 2. Nilai Perbandingan Whole Body Reaction Time Test (visual)

3. Whole Body Reaction Time Test (auditory) Pada Tabel 1 diperoleh nilai rata-rata dari minuman yang diujikan pada tes Whole Body Reaction Time Test (auditory) dengan masing-masing nilai sebesar $0,239 \mathrm{sec}$ untuk plasebo, 0,239 sec untuk teh hijau, 0,274 sec untuk minuman energi dan $0,263 \mathrm{sec}$ pada kopi htam. Nilai signifikansi dari tes Whole Body Reaction Time Test (visual) sebesar 0,348 . Berikut ini adalah nilai perbandingan dari hasil tes waktu reaksi pada Whole Body Reaction Time Test (auditory): 


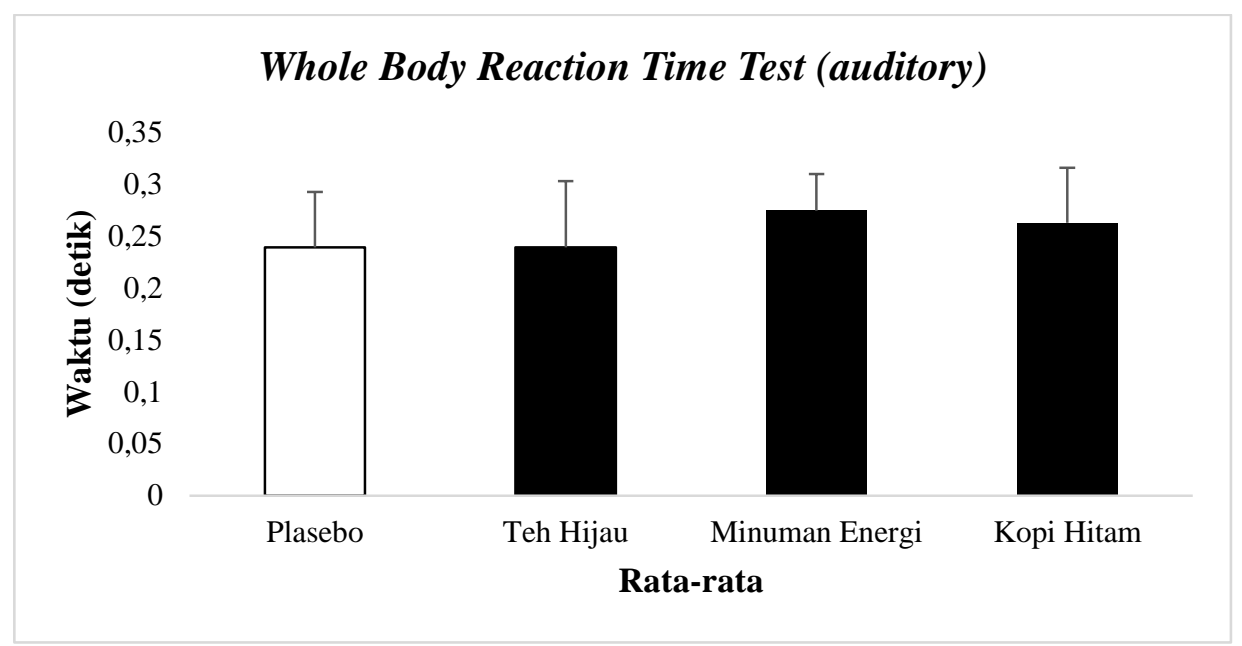

Gambar 3. Nilai Perbandingan Whole Body Reaction Time Test (auditory)

\section{DISKUSI}

Pada dasarnya kafein memang sering dipelajari sehubungan dengan waktu reaksi ${ }^{19}$, namun jumlah kafein dalam satu cangkir kopi tidak dapat mengurangi waktu reaksi. Sementara itu, minuman kafein yang digunakan oleh peneliti hanya mengandung $50 \mathrm{mg}$ kafein dari setiap jenis minuman. Artinya, dari ketiga minuman kafein yang digunakan (Teh Hijau, Minuman Energi, dan Kopi Hitam), hanya teh hijau saja yang sampai 2 cangkir untuk mendapatkan $50 \mathrm{mg}$ kafein. Di sisi lain, Linder (2001), menemukan bahwa meminum satu kaleng baik dari kafein atau kafein bebas kafein tidak memiliki efek yang dapat dideteksi pada waktu reaksi.

Dalam penelitian ini, peneliti tidak merujuk pada dosis kafein yang seharusnya digunakan seperti dalam studi yang dilakukan sebelumnya bahwasannya untuk medapatkan efek yang diinginkan maka dosis kafein yang dikonsumsi sebanyak 4,45 mg / $\mathrm{kg}$ berat badan $^{20}$. Namun peneliti menggunakan sumber pada penelitian yang telah dilakukan dengan menetapkan $\leq 50$ mg untuk penelitiannya kepada sampel yang secara tidak teratur mengkonsumsi kafein setiap harinya ${ }^{21}$. Minuman energi dan kopi menyatakan bahwa dapat meningkatkan kinerja, konsentrasi, dan kecepatan reaksi, meningkatkan kewaspadaan, merangsang metabolisme, dan membuat orang merasa lebih energik ${ }^{2}$. Sementara itu, konsentrasi kafein bervariasi antara minuman yang berbeda dengan kopi, sehingga pada umumnya memiliki nilai tertinggi dibandingkan teh dan beberapa minuman energi ${ }^{3}$. Dalam secangkir kopi, teh hijau dan minuman berenergi yang sering dikonsumsi sama-sama mengandung kafein dalam jumlah yang berbeda. Pengaruh yang didapatkan juga akan berbeda karena perbedaan jumlah kafein yang terdapat di dalam minuman tersebut. Namun, apabila ketiga minuman tersebut memiliki jumlah kafein yang sama maka tidak menuntut kemungkinan akan mendapatkan pengaruh yang sama seperti halnya pada waktu reaksi.

Pada penelitian ini peneliti menyamaratakan jumlah kafein dalam kopi hitam, teh hijau dan minuman energi sebanyak $50 \mathrm{mg}$ kafein. Hal tersebut merujuk pada jumlah kafein dalam satu botol minuman energi yang beredar di Indonesia yang hanya diperbolehkan mengandung $50 \mathrm{mg}$ kafein dalam satu botolnya. Pernyataan tersebut diungkapkan oleh Badan Pengawas Obat dan Makanan (BPOM), sehingga dalam penelitian ini jumlah kafein yang digunakan adalah $50 \mathrm{mg}$ untuk setiap jenis minuman kafein.

Berdasarkan pada gambar 1 mengenai nilai standar deviasi Tes Speed Anticipation Reaction, terlihat adanya beberapa perbedaan nilai walaupun tidak signifikan, dan juga sebaran data dari masing-masing nilai tidak terlampau jauh. Jika dikategorikan dalam Norma Speed Anticipation Reaction (2080 $\mathrm{msec}$ ), maka seluruh nilai rata-rata yang tertera dalam gambar 1 tergolong dalam kategori Semi-Acceptable. Pada gambar2 mengenai nilai standar deviasi Tes Whole Body Reaction (visual), terlihat adanya beberapa perbedaan nilai walaupun tidak signifikan, dan juga sebaran data dari masing-masing nilai tidak terlampau jauh. Jika dikategorikan dalam Norma Whole Body Reaction, maka seluruh nilai rata-rata yang tertera dalam gambar 2 tergolong dalam kategori Bagus. Pada gambar 3 mengenai nilai standar deviasi Tes Whole Body Reaction (auditory), terlihat adanya beberapa perbedaan 
nilai walaupun tidak signifikan, dan juga sebaran data dari masing-masing nilai tidak terlampau jauh. Jika dikategorikan dalam Norma Whole Body Reaction, maka seluruh nilai rata-rata yang tertera dalam gambar 3 tergolong dalam kategori Bagus.

Berdasarkan hasil analasis dan pengolahan data yang telah dilakukan, peneliti dapat menjawab hipotesis yang telah dirumuskan dari hasil penelitian. Temuan dalam penelitian ini yaitu tidak terdapat perbedaan yang signifikan dari hasil penelitian terhadap kedua intrumen tes waktu reaksi. Nilai signifikansi dari ketiga tes waktu reaksi (Speed Anticipation Reaction Sig. $0.706>0.05$, Whole Body Reaction (visual) Sig. $0.877>0.05$, dan Whole Body Reaction (auditory) Sig. $0.348>0.05$ ) seluruhnya di atas 0,05 sehingga $\mathrm{H}_{0}$ diterima. Dengan demikian, tidak terdapat perbedaan yang signifikan terhadap waktu reaksi yang dihasilkan setelah mengkonsumsi berbagai jenis minuman kafein dengan jumlah kafein yang sama.

Penelitian yang dilakukan untuk melihat perbedaan waktu reaksi dari ketiga jenis minuman berkafein ini tidak mendapatkan perbedaan yang signifikan. Hal tersebut diperoleh dari jumlah kafein yang sama dari setiap minuman dan juga jumlah kafein yang terdapat di dalam minuman tersebut memiliki konsentrasi yang sangat sedikit. Peneliti tidak menemukan perbedaan dari ketiga minuman berkafein yang diujikan terhadap waktu reaksi. Namun, peneliti menemukan adanya beberapa hasil yang didapatkan yaitu:

1) Ketiga minuman berkafein yang telah diujikan terhadap waktu reaksi dengan jumlah kafein masing-masing sebanyak 50 $\mathrm{mg}$, tidak menunjukkan perbedaan yang signifikan di antara ketiganya.

2) Mengkonsumsi berbagai jenis minuman berkafein dengan jumlah kafein yang sama tidak akan mendapatkan pengaruh yang berbeda.

3) Mengkonsumsi berbagai jenis minman berkafein untuk mendapatkan waktu reaksi yang diinginkan tentunya harus memperhatikan konsentrasi atau jumlah kafein dalam minuman itu sendiri. Artinya, setiap minuman berkafein memiliki jumlah kafein yang bervariasi dan akan memiliki pengaruh yang berbeda dari setiap jenisnya.

4) Jumlah kafein dalam satu cangkir kopi tidak dapat mengurangi waktu reaksi sehingga tidak akan mendapatkan pengaruh yang baik.

\section{KESIMPULAN}

Berdasarkan analisis data dan pembahasan, dapat diambil kesimpulan bahwa:

1. Tidak terdapat perbedaan yang signifikan terhadap waktu reaksi pada Tes Speed Anticipation Reaction.

2. Tidak terdapat perbedaan yang signifikan terhadap waktu reaksi pada Tes Whole Body Reaction Time (visual).

3. Tidak terdapat perbedaan yang signifikan terhadap waktu reaksi pada Tes Whole Body Reaction Time (auditory).

Dari keseluruhan tes waktu reaksi, dapat disimpulkan bahwa tidak terdapat perbedaan yang signifikan terhadap waktu reaksi yang dihasilkan setelah mengkonsumsi berbagai jenis minuman kafein dengan jumlah kafein yang sama.

\section{DAFTAR PUSTAKA}

1. DelCoso J, Salinero JJ, González-Millán C, Abián-Vicén $\mathrm{J}$, and Pérez-González B. Dose Response effect of a caffeine-containing energy drink on musle performance: a repeated measures design. $J$ of the Internat Soc of Sport Nutr. 2012;9(1):1-10.

2. Valeria Matinuzzi. Effect and Effectiveness of Energy Drinks. Boston; 2012.

3. Heckman MA, Weil J, Gonzalez d ME. Caffeine (1,3,7-trimethylxanthine) in foods: A Comperhensive Review on Consumption, Functionality, Safety, and Regulatory Matters. J of Food Sci. 2010;75(3):R77-87

4. Shelton J. The Effect of Caffeineon Reaction Time of Two Neurocognitive Tests. Theses and Dissertations. 2016; p. 20.

5. Imanudin I. kondisi fisik Bandung: FPOK; 2017.

6. Kosinski RJ. A LIteratur Review on Reaction Time. 2013 September: p. 2.

7. Barone JJ, Roberts RH. Caffeine Consumption. Food Chem Toxicol. 1996;34:119-29.

9. Davis JK, Green JM. Caffeine and anaerobic performance. Sports Med. 2009;39(10):813832.

10. Bazzuchi I, Felici F, Montini MFF, Sacchetti M. Caffeine improves neuromuscular function during maximal dynamic exercise. Muscle Nerve. 2011;43(6):839-844.

11. Brice C, Smith A. The Effect of caffeine on simulated driving, subjective alertness and 
sustained attention. Hum Psychopharmacol. 2001;16(7):523-531.

12. Foskett A, Ali A, Gant N. Caffeine enhances cognitive function and skill performance during simulated soccer activity. $J$ Internat of Sport Nutr. 2009;19(4):410-423.

13. Stuart GR, Hopkins WG, Cook C, Cairns SP.. Multiple effects of caffeine on simulated highintensity team-sport performance. Med of Sci Sport Exerc. 2005;37(11):1998-2005.

14. Schneiker KT, Bishop D, Dawson B, Hackett LP. Effect of caffeine prolonged intermittentsprint ability in team sport athletes. Med of Sci Sports Exerc. 2006;38(3):578-585.

15. Santos VG, et al. Caffeine Reduces Reaction Time and Improves Performance in Simulated-Contest of Taekwondo. J Nutrients. 2014;: p. 637-649.

16. Ferrauti A, Weber K, Struder HK. Metabolic ergogenic effect of carbohydrate and caffeine beverage in tennis. $J$ of Sports Med and Phys Fitness. 1997;37(4):258-266.

17. Lorist MM, Snel J, Kok A, Mulder G. Influence of caffeine on selective attention in well-rested and fatigued subjects. $J$ Psychophysiol.1994; 31(6):525-534.

18. Bealer B. The Miracle of Caffeine New York: The Free Press; 2002.

19. Durlac PJ, Edmunds R, Howard L, Tipper SP. A rapid effect of caffeinated beverages on two chioces reaction time tasks. Nutr Neurosci. 2002;5(6):433-442.
20. Graham TE, Hibbert E, Sathasivam P. Metabolic and excercise endurance effects of coffee and caffeine ingestion. $J$ Appl and Physiol. 1998; 85(3):883-889.

21. Bell DG, McLellan TM. Exercise Endurance $1,3,6$ hours after caffeine ingestion in caffeine users and nonusers. J Appl Physiol. 2002; 93(4):1227-1234.

22. Lorist M, Snel J. Caffeine effect on perceptual and motor processes. Electroencephalogr and Clin Neurophysiol. 1997;102(5):401-414.

23. McLellan TM, et al. Cafeine maintains vigilance and marksmanship in simulated urban operation with sleep deprivation. Aviat Space, and Environ Med. 2005;76(1):39-45.

24. Ligouri A, Robinson JH. Caffeine antagonism of alcohol-induced driving impairment. Drug and Alcohol Depend. 2001;63(2):123-129.

25. Linder GN. The effect of caffeine consumption on reaction time. Bulletin of the South Caroline Academy of Science. 2001;42.

26. Froeliger B, Gilbert DG, McClernon FJ. Effect of nicotine on novelty detection and memory recognition performance: doubleblind, placebo-controlled studies of smokers and nonsmokers. Psychopharmacology. 2009;205(4):625-633. 